\title{
LA-UR-19-28666
}

Approved for public release; distribution is unlimited.

Title: $\quad$ Assessment on DNB performance for high pressure subcooled boiling with modified CASL boiling model

Author(s): Kim, Seung Jun

Intended for: Report

Issued:

2019-08-27 
Disclaimer:

Los Alamos National Laboratory, an affirmative action/equal opportunity employer, is operated by Triad National Security, LLC for the National Nuclear Security Administration of U.S. Department of Energy under contract 89233218CNA000001. By approving this article, the publisher recognizes that the U.S. Government retains nonexclusive, royalty-free license to publish or reproduce the published form of this contribution, or to allow others to do so, for U.S. Government purposes. Los Alamos National Laboratory requests that the publisher identify this article as work performed under the auspices of the U.S. Department of Energy. Los Alamos National Laboratory strongly supports academic freedom and a researcher's right to publish; as an institution, however, the Laboratory does not endorse the viewpoint of a publication or guarantee its technical correctness. 


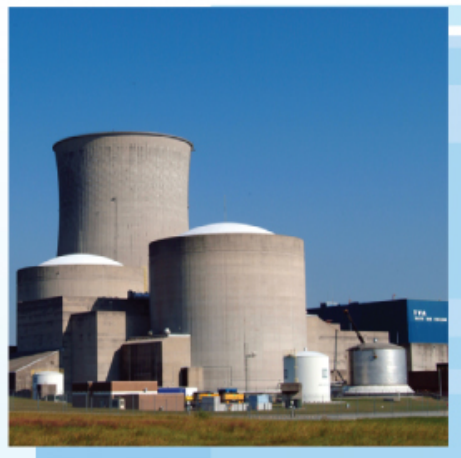

Power uprates

and plant life extension
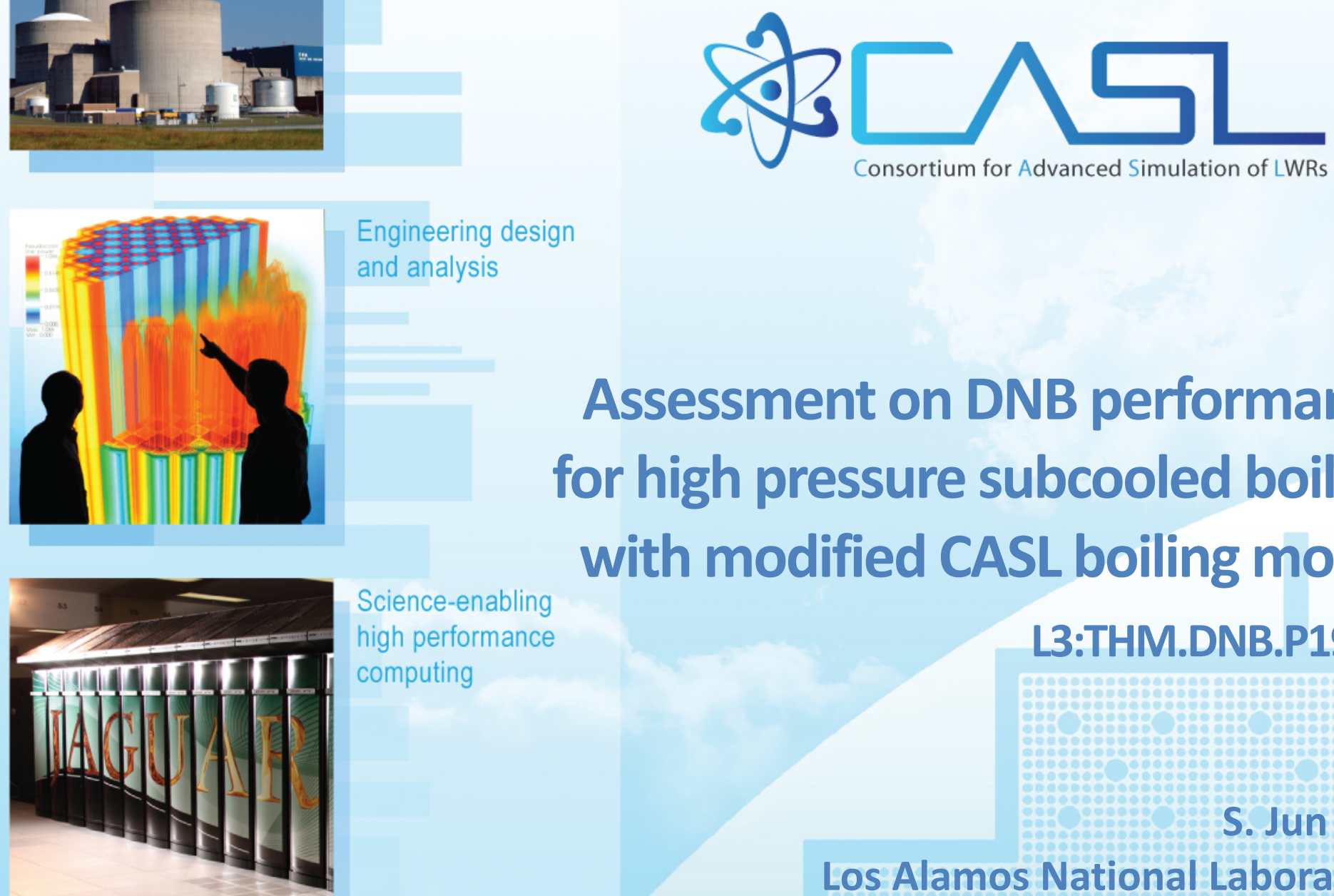

\section{Assessment on DNB performance for high pressure subcooled boiling with modified CASL boiling model}

Science-enabling high performance computing

Engineering design

and analysis

S. Jun Kim Los Alamos National Laboratory

\section{L3:THM.DNB.P19.03}

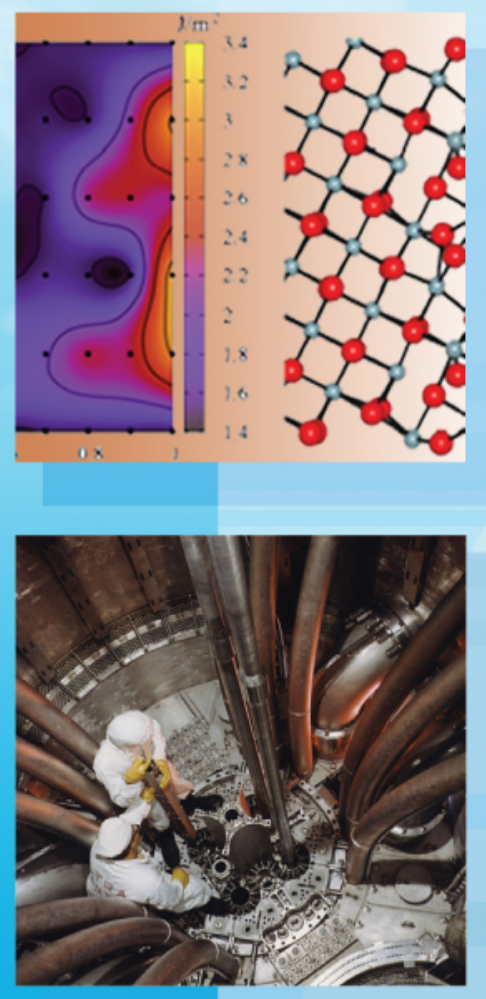

Fundamental science

Plant operational data

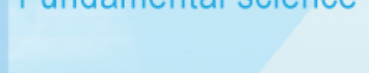


REVISION LOG

\begin{tabular}{|c|c|c|l|}
\hline Revision & Date & Affected Pages & \multicolumn{1}{c|}{ Revision Description } \\
\hline 0 & $08 / 15 / 2019$ & & Original document \\
\hline & & & \\
\hline & & & \\
\hline & & & \\
\hline
\end{tabular}

\section{Document pages that are:}

Export Controlled N/A

IP/Proprietary/NDA Controlled N/A

Sensitive Controlled N/A

\section{Requested Distribution:}

To:

Emilio Baglietto, MIT

W. David Pointer, ORNL

Copy: 


\title{
Assessment on DNB performance for high pressure subcooled boiling with modified CASL boiling model
}

\author{
S. Jun Kim \\ Nuclear Engineering and Nonproliferation \\ Los Alamos National Laboratory \\ Los Alamos, NM 87544
}

\section{Executive Summary}

Understanding and predicting the Departure from Nucleation Boiling phenomena in the nuclear power industry has been a grand challenge due to its large impact on the reactor safety and operational economics. Over the past several years, CASL THM team has extensively investigated and demonstrated a state of art Multiphase CFD framework to provide a high-fidelity DNB simulation capability based on the two-fluid Eulerian model in conjunction with a wall heat flux partitioning approach. The overarching goal of this task is to develop and demonstrate a robust CFD-based DNB model which is capable of predicting an entire boiling history up to the DNB condition in which the wall boiling mode is transitioning from the nucleate boiling mode to the film boiling mode. Three different flow channel configurations (pipe flow, $5 \times 5$ fuel bundle with and without mixing vane tests) were studied and thorough closure sensitivity studies were performed to evaluate the wall boiling and momentum closure effect on the DNB performance. Predicated DNB values were compared to the measurements from high pressure subcooled flow boiling tests resulting in a consistent under-predictive trend for all three validation campaigns in FY16-18. With extensive closure sensitivity study, a modified CASL boiling closure model (i.e. Gen1-FY19) is introduced with the following key changes: 1) improved wall boiling closure for high pressure application, 2) newly calibrated lift and wall lubrication force models with modified interfacial length scale model, and 3) updated liquid phase condensation model calibrated for the subcooled boiling application.

The modified boiling model exhibits an improved DNB predictive behavior against the original model while maintaining a viable robustness in the virtual boiling test. Enhanced accuracy in the DNB performance may be attributed to 1) a realistic wall boiling calculation at high pressure flow boiling condition, and 2) improved void distribution estimation. From the overall DNB performance tests, the Gen1-FY19 model shows maximum deviation of 24\% from measurements. The deviation is even reduced to $7 \%$ when the subcooled temperature is less than $40 \mathrm{~K}$. Interestingly, it can be concluded that the current DNB model is well-suitable for high pressure and less subcooled flow boiling applications, which is close to the actual PWR operating condition. In addition to the improved accuracy, a robustness of the DNB simulation is largely achieved in most of validation test except for a few high subcooled test cases. As a collaborative effort, thorough model evaluations are performed between the THM team to increase the feasibility and applicability of FY19-GEN1 model: 1) the validation works of axial and radial void profiles are performed by INL, 2) DNB sensitivity tests with pipe flow are done by LANL, and 3) $5 \times 5$ tests are done by WEC. Three counterpart's tests were crossed checked and mutually beneficial to the overall model validation. 


\section{Contents}

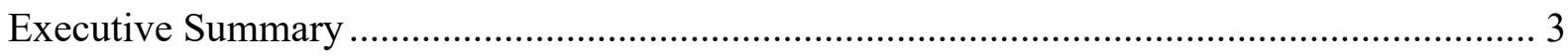

1. Background: Recap the previous DNB validation campaigns........................................ 6

2. CASL boiling model and DNB detection approach................................................... 7

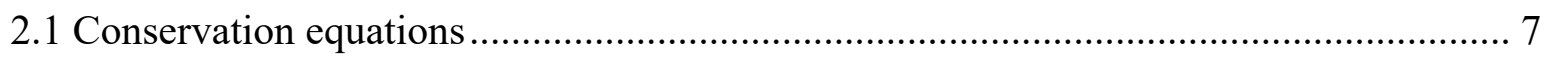

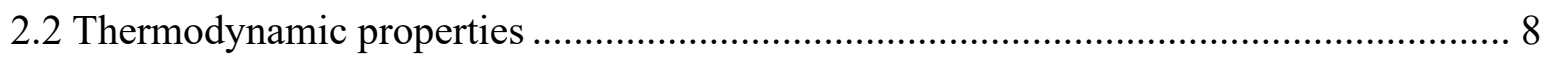

2.3 Summary of closure selection in GEN1-FY19 model .............................................. 9

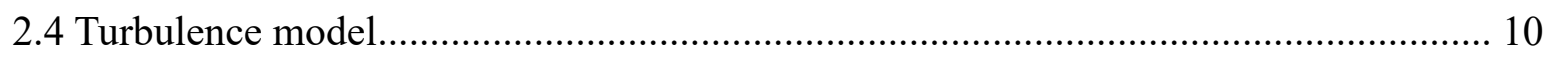

2.5 Interfacial momentum transfer model.................................................................. 10

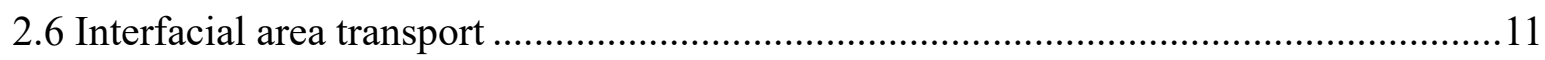

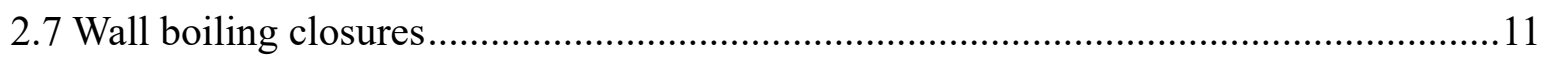

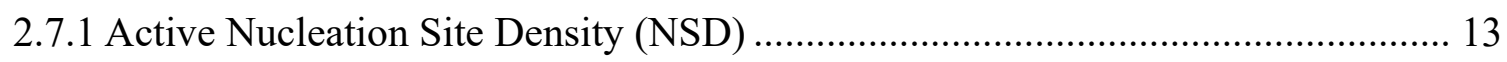

2.7.2 Bubble Departure Diameter (BDD) ………….................................................. 14

2.7.3 Bubble Departure Frequency (BDF)................................................................ 14

3. DNB performance with Gen1-FY19 CASL model................................................... 15

3.1 DNB performance review in the previous validation tests ......................................... 15

3.2 Convergence check for the DNB tests .................................................................. 16

3.3 Axial and radial void characteristics with different heat flux conditions ..................... 18

3.4 DNB performance comparison between original model and modified model .............. 19

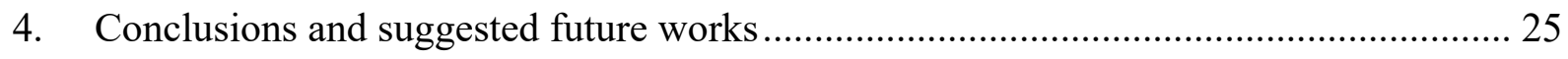

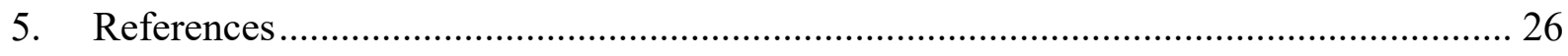




\section{Figures}

Figure 1 A visual summary of previous DNB validation campaigns (FY16 FY18) ............. 6

Figure 2 DNB detection criterion based on a critical void profile near the wall ................... 12

Figure 3 Nucleation site density model (Li model vs previous models) ............................. 13

Figure 4 Bubble departure diameter with pressures (Kocamustafaogullari model) ............... 14

Figure 5 Results on DNB validation campaign 1 with original CASL model....................... 15

Figure 6 Wall temperature, K-value, Energy monitors with incremented heat flux up to DNB where, temperature excursion is taking place and K, Energy transfer become non-zero.................. 18

Figure 7 An example of temperature, density, and void profile calculation for the DNB test. 18 Figure 8 Radial void distribution along with increasing heat flux up to $82.5 \%$ of CHF ........ 19

Figure 9 Wall peak temperature monitoring with incremental heat flux ............................ 21

Figure 10 Prediction performance evaluation by comparing measurements vs calculations .. 23

Figure 11 DNB performance with different subcooled inlet temperature levels .................. 24

\section{Tables}

Table 1. The ranges of validity for IAPWS-IF97 correlation ............................................. 8

Table 2. Gen1-FY19 CASL boiling closure selection for high pressure DNB application ....... 9

Table 3. Selected closure comparison between Gen1-FY17 and Gen1-FY19..................... 20

Table 4. A direct comparison of DNB values between Gen1-FY17 and Gen1-FY19 ............ 22 


\section{L3.THM.DNB.P19.03}

\section{Background: Recap the previous DNB validation campaigns}

Subcooled flow boiling can provide an effective heat transfer mode in a heat flux-controlled system such as nuclear power plant. This enhanced heat transfer mode, however, is limited by the Critical Heat Flux (CHF) or the Departure from Nucleate Boiling (DNB). Beyond this critical point, the system encounters a radial reduction of heat transfer coefficient due to the transition from nucleation boiling to the film boiling condition, and experiences a temperature excursion at the heating surface which hampers down the safety and integrity of the heating surface of the fuel rods. In Pressurized Water Reactor (PWRs), predicting the CHF or DNB is a critical design parameter and important operational issue as it is related to the reactor safety and economics. Over the past four years, CASL THM has been extensively demonstrating the DNB modeling capability for subcooled flow boiling application for high pressure operating condition. Below is a summary of previous DNB validation campaign efforts

- In FY16, The CASL baseline model was developed and tested for pipe flow DNB. A virtual boiling test methodology was proposed to evaluate the DNB predictive performance. The baseline boiling closures were selected and implemented into a simple pipe flow DNB test at the high-pressure condition (e.g. 138bar).

- A numerical robustness was obtained in most of the DNB tests except for either highly subcooled flow test and high void test; in other words, when the inlet temperature is largely subcooled or high void at the outlet is observed, the simulations encounter with numerical convergence issues.[1]. Predicated DNB was directly compared to corresponding measurements showing under-predictive behavior up to $33 \%$ deviation.

- In FY17, we tested the 5x5 fuel bundle flow configuration DNB test with and without mixing vane spacer grids. The same model was tested in more complex configurations.

- Under-predictive behaviors were still shown in these tests. The deviations from the measurements are varied from $-25 \sim-50 \%$. Note that the mixing vane test case exhibits relatively larger deviation compared to the non-mixing vane test.[2]

- In FY18, we scrutinized the baseline boiling model and identified what would be the potential cause of under-prediction [3]. Based on closure sensitivity study, a modified boiling closure model was introduced for FY19 validation campaigns (see Figure 1).

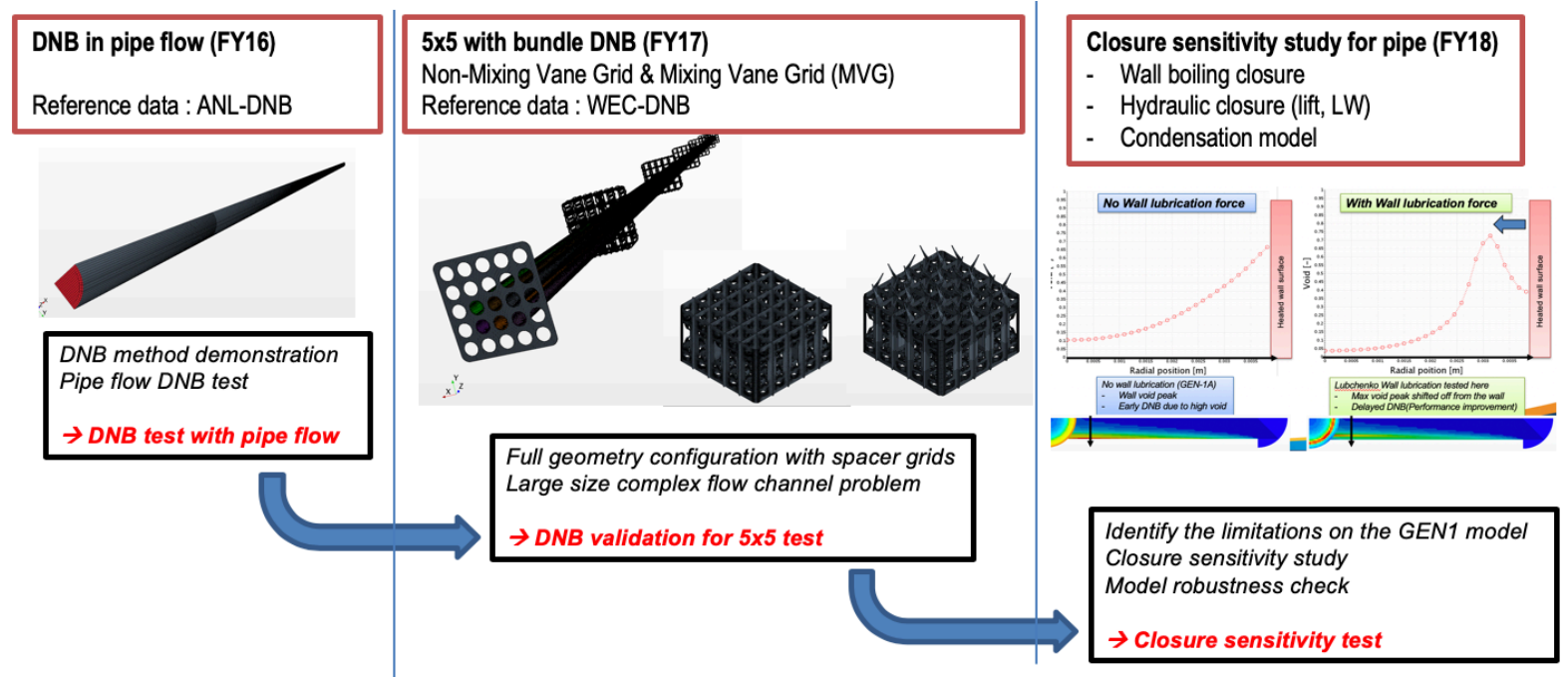

Figure 1 A visual summary of previous DNB validation campaigns (FY16 FY18) 


\section{CASL boiling model and DNB detection approach}

The CASL baseline boiling model uses the Eulerian two-fluid model in conjunction with heat flux partitioning wall-boiling approach to describe boiling associated flow phenomena. The model tracks the local void fraction near the heated surface to identify the inception of the DNB which transitions from the nucleate boiling state to the film boiling stage. When it comes to local void fraction in the model, interfacial liquid-vapor mass, momentum and energy equation are solved to close the system of conversation equations. In DNB simulations all voids are created at the heated surface by a calculation of evaporation mass flux which is converted from evaporation heat flux using the latent heat energy equation. Therefore, an accurate evaporation heat flux calculation is a significantly important variable to quantify the void information near the wall.

In particular, the current boiling model is based on the bubbly layer theory proposed by Pei and Weisman [4]. The DNB criterion is solely based on void fraction near the wall in the computation cells. In order to accurately predict the boiling crisis in the CFD model, the void transfer mechanism should be carefully examined in the wall boiling closure as well as associated interfacial momentum closures. However, it should also be noted that both interfacial momentum transfer closures and wall boiling closures are highly dependent on interfacial length scale and bubble size distribution at the operating conditions. In addition to this, the applicability of selected closures at high pressure operating conditions should be also taken into consideration for the DNB boiling test.

\subsection{Conservation equations}

In the two-fluid model, mass, momentum, and energy equations are modeled for each phase in conjunction with an interfacial transport term. A brief description on the transport equation applied is summarized below with an interpretation related to interfacial transport concept. Note that more detailed explanations on conservation equations are documented in previous reports $[2,3]$.

The conservation of mass for phase $\mathrm{k}$ is:

$$
\begin{gathered}
\frac{\partial}{\partial t}\left(\alpha_{k} \rho_{k}\right)+\nabla \cdot\left(\alpha_{k} \rho_{k} u_{k}\right)=\sum_{i=1}^{N}\left(\dot{m}_{k i}-\dot{m}_{i k}\right) \\
\sum_{k} \alpha_{k}=1
\end{gathered}
$$

where, $\alpha_{k}$ is volume fraction of phase $\mathrm{k}, \rho_{k}$ is phase density, $u_{k}$ is phase velocity, $\dot{m}_{k i}$ and $\dot{m}_{i k}$ are mass transfer rates to and from the phase, and $\mathrm{N}$ is the total number of phases.

Note that mass transfer rate in the mass conservation equation is calculated based on the void generation (i.e. liquid phase to vapor phase) by the evaporation term in wall boiling closure and liquid generation (i.e. vapor phase to liquid phase) by the condensate model at the bulk fluid region.

The conservation of momentum for phase $\mathrm{k}$ is:

$$
\begin{gathered}
\frac{\partial}{\partial t}\left(\alpha_{k} \rho_{k} u_{k}\right)+\nabla \cdot\left(\alpha_{k} \rho_{k} u_{k} u_{k}\right)-\nabla \cdot\left(\alpha_{k}\left(\tau_{k}+\tau_{k}^{t}\right)\right)=-\alpha_{k} \nabla P+\alpha_{k} \rho_{k} g+M \\
M=F_{D}+F_{T D}+F_{L}+F_{V M}+F_{W L}+\sum_{i=1}^{N}\left(\dot{m}_{k i} u_{k}-\dot{m}_{i k} u_{i}\right)
\end{gathered}
$$


where, $\tau_{k}$ and $\tau_{k}^{t}$ are laminar and turbulence shear stresses, $\mathrm{P}$ is pressure, and $\mathrm{M}$ is the sum of the interfacial momentum transfer that includes drag, lift, wall lubrication, turbulence disperse force, and virtual mass force.

The conservation of energy for phase $\mathrm{k}$ is:

$$
\begin{array}{r}
\frac{\partial}{\partial t}\left(\alpha_{k} \rho_{k} h_{k}\right)+\nabla \cdot\left(\alpha_{k} \rho_{k} u_{k} h_{k}\right)-\nabla \cdot\left(\alpha_{k}\left(\lambda_{k} \nabla T_{k}+\frac{\mu_{t}}{\sigma_{h}} \nabla h_{k}\right)\right)=Q \\
Q=\alpha_{k} \frac{D P_{k}}{D t}+\alpha_{k}\left(\tau_{k}+\tau_{k}^{t}\right): \nabla u_{k}+\sum_{i \neq k} Q_{k i}+\sum_{(i k)} Q_{k}+\sum_{i \neq k}\left(m_{k i} h_{k}-m_{i k} h_{k}\right)
\end{array}
$$

where, $h_{k}$ is phase enthalpy, $\lambda_{k}$ is thermal conductivity in phase $\mathrm{k}, \mathrm{T}$ is temperature, $\mu_{t}$ is turbulent viscosity, $\sigma_{h}$ is turbulent Prandtl number, and Q is the interfacial heat transfer and other heat source.

Again, note that the void creation term (i.e. $m_{k i}$ ) by evaporation and the liquid generation term (i.e. $m_{i k}$ ) by condensate models are used in equation (6) to quantify interfacial energy transfer (Q). Thus, a selection of appropriate wall boiling closures (void generation) and condensate (liquid generation) models are very important since they are tightly coupled with interfacial mass and energy conservation.

\subsection{Thermodynamic properties}

In the current simulation, thermodynamic properties for liquid and vapor phases are defined by IAPWS-IF97 correlation at the given system pressure and temperature. The correlation provides a fundamental polynomial equation for the specific Gibbs free energy, and then density and other thermodynamic properties are calculated for both liquid and vapor, based on the correlation. Thus, density and all thermodynamic properties for liquid and vapor phases are changed along with the flow condition. Note that the IAPWS-IF97 correlation used in the current simulation are only valid within the temperature and pressure ranges listed in Table 1. It is also worth noting that all simulation cases in this study fall within the validity window, thus no numerical issue with IAPWSIF97 feature is observed in the current test.

Table 1. The ranges of validity for IAPWS-IF97 correlation

\begin{tabular}{|l|l|}
\hline Component & Ranges of Validity \\
\hline Liquid phase: IAPWS-IF97(water) & $272.15 \mathrm{~K}<\mathrm{T}<623.15 \mathrm{~K}, \mathrm{P}<100 \mathrm{Mpa}$ \\
\hline Vapor phase: IAPWS-IF97(steam) & $272.15 \mathrm{~K}<\mathrm{T}<1073.15 \mathrm{~K}, \mathrm{P}<100 \mathrm{Mpa}$ \\
\hline
\end{tabular}

Some of the DNB tests in FY16 were conducted without IAPWS, which implies constant thermodynamic properties for both liquid and vapor phases were used for subcooled flow boiling. Although some of the DNB predictions slightly deviated between constant properties test and variable properties test, a further thorough investigation was not pursued at that time. Instead, the dynamic thermodynamic properties approach is selected as a reference as it is believed that the IAPWS model captures the realistic thermodynamic properties in a two-phase environment. 


\subsection{Summary of closure selection in GEN1-FY19 model}

An overall numerical approach for DNB boiling simulation is briefly summarized below. The closure models are selected from the lessons learned from FY18 sensitivity work. The detailed multiphase interfacial closures and boiling closure correlations selected for the DNB validation work are listed in Table 2. Note that this final selected model is consistently used within all of THM collaborators for FY19 task.

Table 2. Gen1-FY19 CASL boiling closure selection for high pressure DNB application

\begin{tabular}{|c|c|}
\hline Interfacial transfer and Boiling closure & Selected model and correlation \\
\hline \multicolumn{2}{|l|}{ Interfacial momentum/energy transfer } \\
\hline$>$ Lift force & Sugrue-Podowski lift \\
\hline$>$ Drag force & Tomiyama model with contamination \\
\hline$>$ Turbulence dispersion force & Turbulent dispersion $\operatorname{Pr}=1.0$ \\
\hline$>$ Wall Lubrication force & Lubchenko model \\
\hline \multicolumn{2}{|l|}{ Interphase mass/energy transfer } \\
\hline$>$ Liquid phase condensate & Kim-Park condensation model \\
\hline$>$ Vapor phase condensate & $\mathrm{Nu}=26$ \\
\hline$>$ Interfacial Area density & Symmetric particle assumption \\
\hline$>$ Interaction Length Scale & $\begin{array}{l}\text { S-gamma with Sauter mean diameter } \\
\text { - } \quad \text { Limiter: } 1 \mathrm{e}-6 \mathrm{~m} \\
\text { - } \quad \text { Coefficient: } 0.2\end{array}$ \\
\hline \multicolumn{2}{|l|}{ Wall boiling model } \\
\hline$>$ Convective heat flux & Single phase turbulent convection model \\
\hline$>$ Evaporation heat flux & $\begin{array}{l}\text { 1. Bubble departure diameter model } \\
\text { (Kocamustafaogullari) } \\
\text { 2. Bubble departure frequency (Cole) } \\
\text { 3. Nucleation site number density } \\
\text { (Modified Li with NSD limiter) }\end{array}$ \\
\hline$>$ Quenching heat flux & $\begin{array}{l}\text { Quenching HTC: Del Valle Kenning model } \\
-\quad \text { Wait coefficient: } 0.8 \\
\text { Bubble induced fraction: Kurul-Podowski } \\
\text { - Area coefficient: } 2.0\end{array}$ \\
\hline$>$ Wall boiling relaxation & Wall boiling Under-relaxation factor: 0.5 \\
\hline$>$ Wall Dry-out Area Fraction & $\begin{array}{l}\text { Wall Dry-out breakpoint: } 0.9 \\
\text { Bubbly Layer Relaxation Faction: } 1.0 \\
\text { Bubbly Layer Option: Fixed Y+: } 200\end{array}$ \\
\hline
\end{tabular}

Baseline Boling model frame and DNB detection criterion

- Eulerian -Eulerian based Two fluid model

- Steady RANS model for both phases with standard k-e model

- High Y+ wall treatment function applied for boundary layer

- IAPWS-IF97 correlation for both phase thermodynamic properties

- Wall heat flux partitioning approach (see detailed in Table 2) 
- $\quad$ DNB criterion: Wall void fraction $=90 \%$ at $\mathrm{Y}+2000$

- DNB test procedure: Incremental heat flux applied while monitoring wall temperature

Main changes applied in the FY19 model are: 1) advanced lift + wall lubrication model, 2) KimPark's condensation model + the Sauter mean diameter distribution by the S-Gamma model, and 3) modified evaporation heat flux estimation with newly developed bubble departure diameter and nucleation site density models. A detail model description on the changed closure model will be addressed in section 2.6, and its impact on the DNB performance is reported in Chapter 3.

\subsection{Turbulence model}

Standard k-e turbulence model with high $\mathrm{Y}+$ wall treatment is selected to solve flow turbulence in both phases. Regarding near wall mesh strategy, it should be noted that the $\mathrm{Y}+$ values of approximately $70 \sim 100$ were required to capture appropriate boiling heat transfer. Bubble induced turbulence is not considered in this study as the work of Magolan have investigated a balance between production and dissipation of bubble-induced turbulence at high Reynolds number condition, concluded that the shear induced turbulence is the dominant component [5]. In general, turbulence effects on various fluid applications should be a checking point for high-fidelity calculations. In this bubbly flow conditions with void fractions below 30\%, however, the shear induced component is dominant, and the adoption of the standard k-e approach provides reasonable predictions on DNB performance. However, there might be some effect on the void profile in the radial direction associated with different turbulence models since the turbulence dispersion force might be slightly changed between turbulence models.

\subsection{Interfacial momentum transfer model}

Equation 4 in 2.1 represents the sum of five key momentum sources $\left(F_{D}+F_{T D}+F_{L}+F_{V M}+F_{W L}\right)$. Those interfacial momentum transfer models can be divided into two groups: 1) drag force and 2) non-drag force. Drag force usually governs interfacial momentum transfer along with flow direction which is not directly related to lateral void distribution. Non-Drag forces include lift force $\left(F_{L}\right)$, and wall lubrication force $\left(F_{W L}\right)$. The combination of non-drag forces determines the lateral void distribution encompassing the near wall boiling region and bulk fluid region. Since void prediction is a most critical variable for the DNB triggering algorithm, non-drag force closure should be examined and validated with high resolution void distribution experimental data. However, most DNB tests only report system extrema such as critical heat flux, exit outlet temperature, and some pressure drop. Thus, high-resolution void data are rarely obtained from any open literature. Unfortunately, this is a most challenging component in a successful DNB model validation test.

The drag force model has two components: an average part and a fluctuating part. The average drag force is given by:

$$
F_{D}=\frac{3 \alpha_{g} \rho_{l}}{4 d_{B}} C_{D} \alpha_{g}^{4}\left|u_{l}-u_{g}\right|\left(u_{l}-u_{g}\right)
$$

where $d_{B}$ is the bubble diameter and $C_{D}$ is the drag coefficient, estimated by Tomiyama [6] for a mildly contaminated two fluid system. The fluctuation part of drag force is usually calculated as turbulent dispersion force, which plays an important role in taking the vapor bubbles from the near 


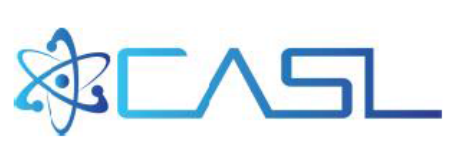

L3.THM.DNB.P19.03

wall region to the bulk liquid.

$$
F_{T D}=-2 \frac{v_{l}^{t}}{\alpha_{g} \alpha_{l} \sigma_{a}} \nabla \alpha_{g}
$$

Here, $v_{l}^{t}$ is the turbulent kinematic viscosity of liquid phase and $\sigma_{a}$ is the turbulent Prandtl number (default value of 1 is used in this study).

Regarding non-drag forces, lift and wall lubrication force models are newly implemented in the FY19 boiling model. Sugrue lift model incorporating a wobbly bubble effect, and Lubchenko model accounting for wall lubrication effect based on the postulated lift-off diameter concept developed by MIT are implemented in the current study [7,8]. Those newly adopted boiling closure can help an improved lateral void estimation near at the wall, which will prevent the premature DNB triggering mechanism observed in the previous validation campaign.

$$
\begin{gathered}
F_{L}=C_{L, \text { Sugrue }} \alpha_{g} \rho_{l}\left[\left(u_{l}-u_{g}\right) \times\left(\nabla \times u_{l}\right)\right] \\
F_{W L}=-C_{W L, \text { Lubchenko }}\left(y_{w}\right) \alpha_{g} \rho_{l} \frac{\left|u_{l}-u_{g}\right|^{2}}{d_{B}}
\end{gathered}
$$

\subsection{Interfacial area transport}

As described earlier in this chapter, it is also critical to correctly model a set of multiphase interfacial area transport closures as those closures play a significant role in the mass, energy, and momentum equations (see Eq. 1, 3, 5, and 6). Phase change between liquid and vapor can be modeled as vapor generation by evaporation near or at the wall and liquid generation by condensation in the sub-cooled bulk fluid region. With this in mind, the bubble size distribution is one of many unknowns in the subcooled flow boiling regime due to lack of high-resolution experimental measurement at a certain pressure condition. In the FY19 model, the Sauter mean diameter distribution in the liquid region is calculated by the two equation S-gamma model. The S-gamma model is a model similar to the interfacial area transfer equations including a set of chaotic bubble dynamics such as bubble breakup and coalescence, but their source items are different. The S-gamma model represents the bubble size distribution using the method of moment approach. Thus, the bubble size distribution is assumed to have a pre-defined shape and this shape is retained during the bubble profile calculation. A detailed description of the S-gamma model can be found in Lo and Rao's paper. [9]

\subsection{Wall boiling closures}

In parallel to void distribution related closures, wall boiling closures are effectively contributing to the void profile calculation near wall which is the sole criterion of DNB detection in the current approach shown in Figure 2. In general, wall heat flux can be viewed as three parts according to a wall heat partitioning model; 1) single phase convective heat flux, 2) evaporative heat flux, and 3) quenching heat flux. The wall dry-out factor $\left(K_{d r y}\right)$ is utilized to smoothly transition nucleate flow boiling mode to film boiling by vapor only heat transfer mode as shown below:

$$
q_{w}^{\prime \prime}=\left(q_{\text {Conv.liquid }}^{\prime \prime}+q_{\text {Evaporation }}^{\prime \prime}+q_{\text {Quenching }}^{\prime \prime}\right)\left(1-K_{\text {dry }}\right)+q_{\text {Conv.vapor }}^{\prime \prime} K_{\text {dry }}
$$

Here, $K_{d r y}$ is a mathematical function composed of local void fractions at a certain distant from the wall (See reference 2 for detailed information). Equation 11 numerically illustrates how the 


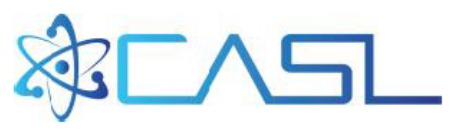

\section{L3.THM.DNB.P19.03}

wall boiling model operates from sub-cooled nucleate boiling (i.e. normal mode) to departure from nucleate boiling (i.e. DNB mode). There are two conditions incorporated in the wall boiling model. The first term in the equation reflects a normal nucleate boiling regime in which the heat flux is still well below DNB, while the second term describes a DNB condition when bubble generation starts sufficiently covering the heated surface and finally turns into a film boiling condition.

$$
\begin{aligned}
& q_{\text {Conv.liquid }}^{\prime \prime}=\frac{\rho_{l} C_{p, l} u_{l}^{*}}{T_{l}^{+}}\left(T_{w}-T_{l}\right) \\
& q_{\text {Quenching }}^{\prime \prime}=2 K_{\text {quenching }} f \sqrt{\frac{\rho_{l} C_{p, l} k_{l} t_{w}}{\pi}}\left(T_{w}-T_{l, q u e n c h}\right) \\
& q_{\text {Conv.vapor }}^{\prime \prime}=\frac{\rho_{v} C_{p, v} u_{v}^{*}}{T_{v}^{+}}\left(T_{w}-T_{v}\right)
\end{aligned}
$$

where $u_{l}^{*}$ and $u_{v}^{*}$ are the velocity of liquid and vapor near the heated wall surface and $T_{l}^{+}$and $T_{v}^{+}$are non-dimensional parameters for liquid and vapor. Those near wall velocities and dimensionless temperature parameters are all calculated through wall functions. $C_{p, l}$ and $C_{p, v}$ are liquid and vapor specific heat. $h_{f g}$ is the latent heat of evaporation in the phase change, and $K_{\text {quenching }}$ is the bubble influence area coefficient.

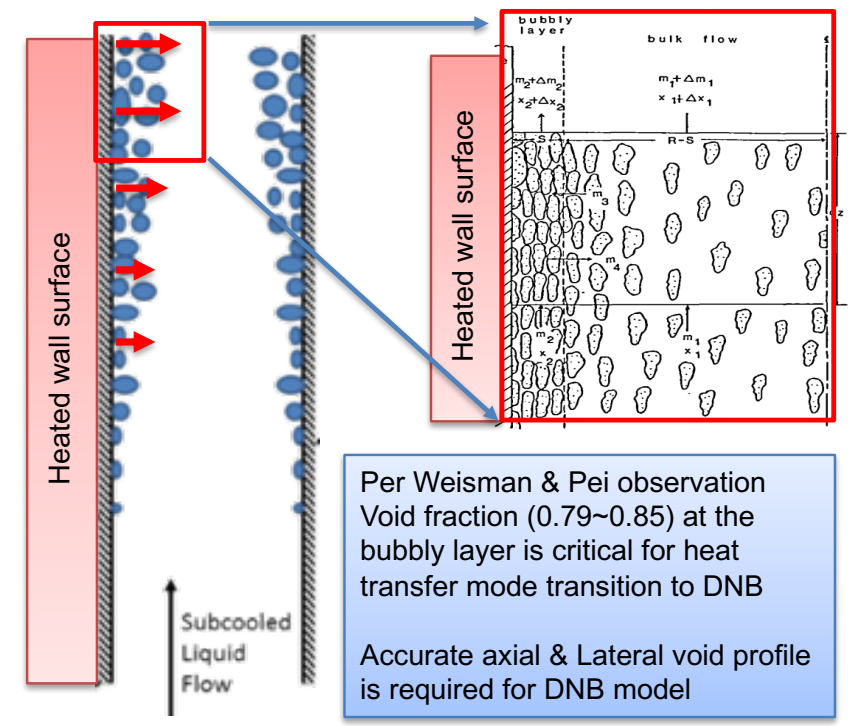

\section{Heat Transfer mode transition}

$\rightarrow$ DNB triggering mechanism

$$
q_{\text {wall }}^{\prime \prime}=(1-K)\left(q_{f c}^{\prime \prime}+q_{q c}^{\prime \prime}+q_{e v}^{\prime \prime}\right)+K q_{g a s}^{\prime \prime}
$$

Bubble layer theory

Critical near-wall void fraction

$\alpha_{\text {crit. }}=0.79 \sim 0.85$ (Weisman, 1983)

$\mathrm{K}=$ smooth blending function

\section{$\underline{K \text { value by wall void }}$}

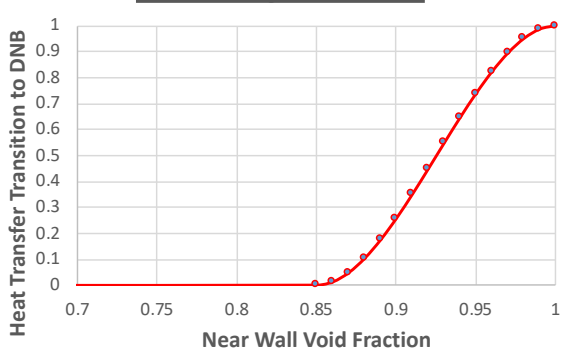

Figure 2 DNB detection criterion based on a critical void profile near the wall

Among the three heat flux partition terms in wall modeling model, the evaporation heat flux term dominates mostly the wall dry-out factor as it determines the void creation. As the current DNB triggering mechanism is purely based on a local void near wall, void generation term calculated by evaporation heat flux must be a more practical calibration factor from the DNB prediction performance standpoint. Thus, the evaporation heat flux term should be carefully calibrated for desired applications (e.g. high-pressure flow boiling DNB).

$$
q_{\text {Evaporation }}^{\prime \prime}=N_{a} f_{d}\left(\frac{\pi D_{d}^{3}}{6}\right) \rho_{g} h_{f g}
$$

where, $N_{a}, D_{d}$ and $f_{d}$ denote active nucleation site density, bubble departure diameter, and 


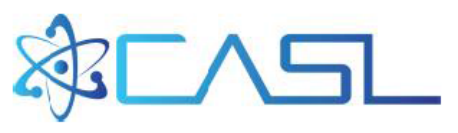

bubble departure frequency, respectively. Equation (15) implies that an amount of equilibrium evaporation heat flux by a mass flux of bubble generation (i.e. nucleation site density $\times$ bubble departure diameter $\times$ bubble departure frequency) multiplied with latent heat and vapor density at the given system pressure. Thus, one should have a wise selection of three wall boiling closures to quantitatively calculate evaporative heat flux. More detailed discussion on those closure selections are discussed below.

\subsubsection{Active Nucleation Site Density (NSD)}

The nucleation site density calculates the number of departing bubbles on the heated surface over a unit area. In the previous validation tests, we tested two methods; 1) Lemmart-Chawla model and 2) Hibiki-Ishii model. Both models were basically correlated based on various experimental measurements. Usually the original Lemmart-Chawla model predicts relatively smaller site density compared to Hibiki-Ishii model at a given pressure condition. In the FY19 model, active nucleation site density is estimated by the modified Li model (2016):

$$
\begin{gathered}
N_{\mathrm{w}}=N_{0}(1-\cos \theta) \exp \times f(P) \times \Delta T_{\text {sup }}^{\left(A \Delta T_{\text {sup }}+B\right)} \\
N_{0}=1000\left[\frac{\text { site }}{m^{2}}\right] \\
f(P)=26.006-3.678 \exp (-2 P)-21.907 \exp \left(-\frac{P}{24.065}\right) \\
A=-0.0002 P^{2}+0.0108 P+0.0119 \\
B=0.122 P+1.988
\end{gathered}
$$

where $\mathrm{P}$ is the system pressure with unit of MPa. $\theta$ is contact angle. $\Delta T_{\text {sup }}$ is the wall superheat. The Li's NSD model strives to account for the system pressure, surface characteristics, and the wall superheat when the nucleation site density is correlated based on empirical data, which is a similar approach to Hibiki model with slightly improved prediction performance illustrated in Figure 3 . In addition to Li's model, we implement a limiter factor in the Li's model by estimating the possible max NDS value from analytic calculation based on bubble size.
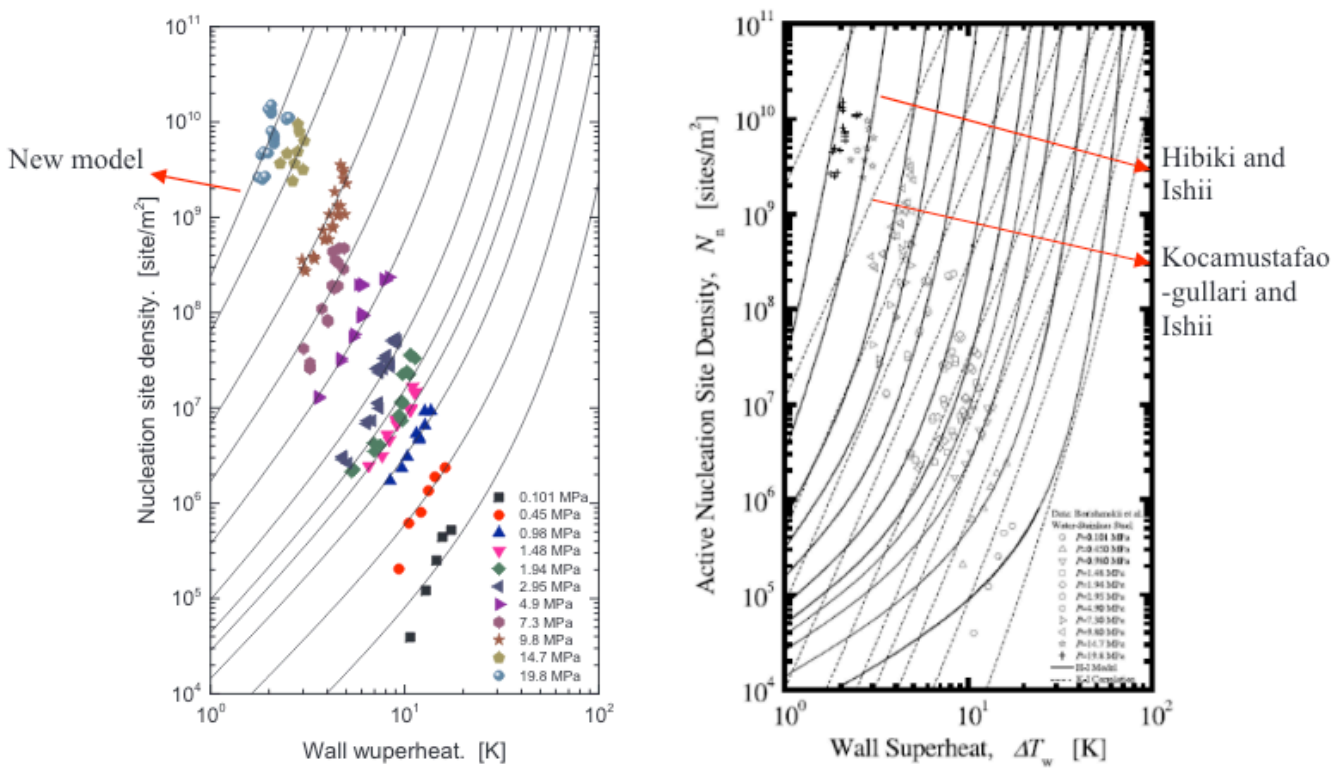

Figure 3 Nucleation site density model (Li model vs previous models) 


\subsubsection{Bubble Departure Diameter (BDD)}

The bubble departure diameter model determines the diameter of departing bubbles at the heated wall when it leaves the nucleation site. Along with nucleation site density, bubble departure diameter is one of the most challenging wall boiling closure models. While there exists numerous analytic correlations and semi-empirical models, a viable bubble departure diameter at high pressure and flow boiling condition is still yet to be introduced. In this study, the bubble departure diameter is estimated by Kocamustafaogullari model (1983):

$$
d_{d}=2.64 \times 10^{-5} \theta \sqrt{\left(\frac{\sigma}{g \Delta \rho}\right)}\left(\frac{\Delta \rho}{\rho_{g}}\right)^{0.9}
$$

Per the Kocamustafaogullari model, bubble departure diameter varies widely with different pressures. For example, at 1 bar, bubble departure diameter by the model is calculated to $2 \mathrm{~mm}$, but the value reduces to $0.006 \mathrm{~mm}$ at high pressure (e.g. $138 \mathrm{bar}$ ) as shown in Figure 4. The validity of Kocamustafaogullari model is not evaluated in this study due to lack of available experimental measurements, however, it should be noted that bubble departure diameter change inevitably leads to more calibration in other closures (e.g. bubble departure frequency, active nucleation site density.

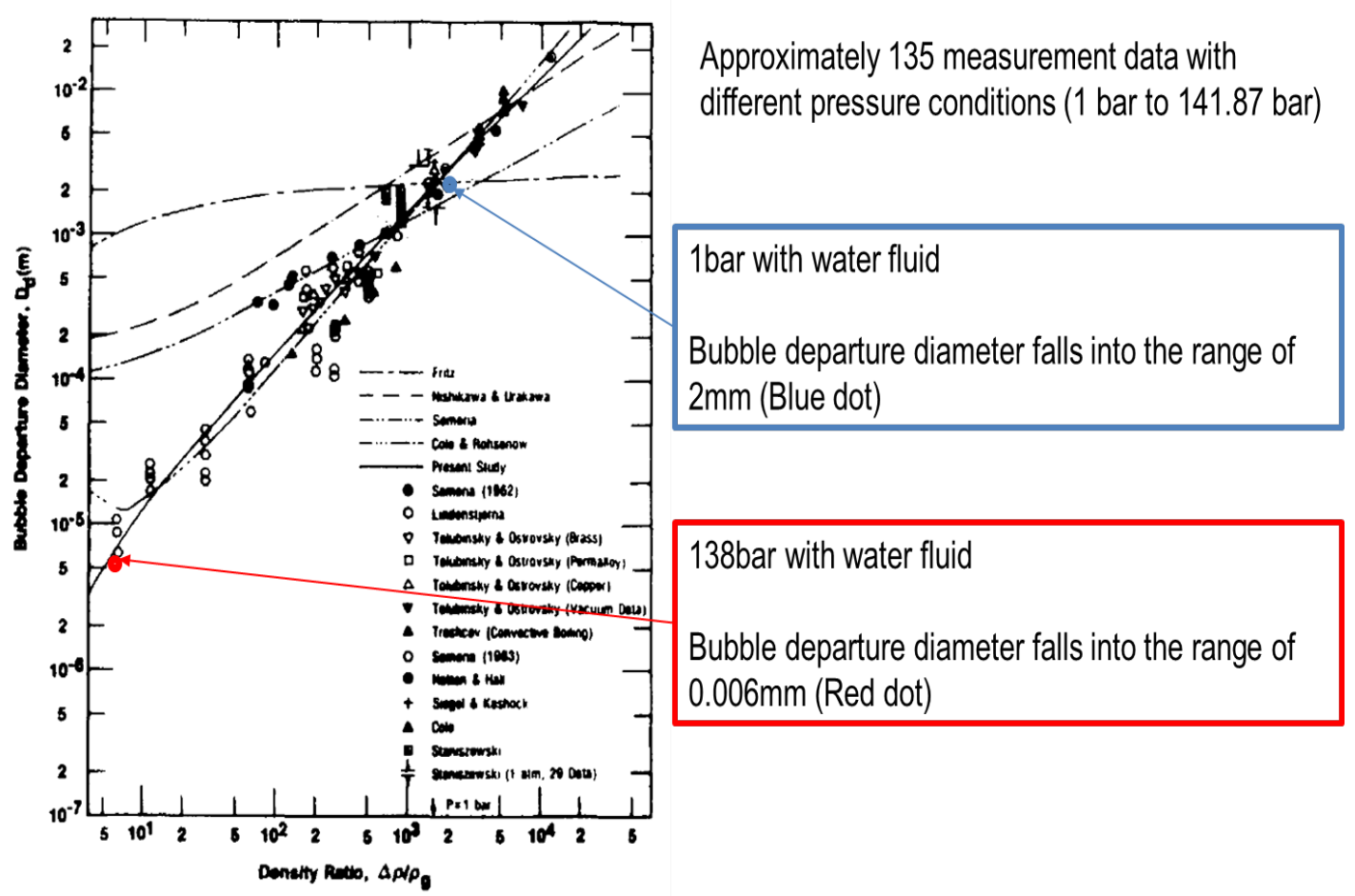

Figure 4 Bubble departure diameter with pressures (Kocamustafaogullari model)

\subsubsection{Bubble Departure Frequency (BDF)}

The bubble departure frequency model follows Cole's approach. Cole assumes that a typical bubble rise velocity is determined by bubble departure diameter using a force balance at the bubble departing surface.

$$
f=\sqrt{\frac{4 g\left(\rho_{l}-\rho_{g}\right)}{3 D_{d} \rho_{l}}}
$$




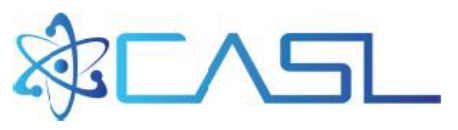

L3.THM.DNB.P19.03

In this model, the waiting time between bubble departure and the activation of the next bubble is assumed to be $80 \%$ of the total bubble departure time in the pool boiling scenario. Therefore, a compounding effect between departure diameter and frequency should be accounted for when the wall boiling closures are selected for the desired DNB model for high pressure subcooled flow boiling application.

\section{DNB performance with Gen1-FY19 CASL model}

\subsection{DNB performance review in the previous validation tests}

Pipe flow and 5x5 fuel bundle channel DNB tests are modeled using original Gen 1 boiling model in past years (FY17-18). Both flow configuration tests are conducted under a PWR-like high pressure condition (138 160 bar). The detailed operating conditions are summarized below.

Validation campaign 1: Pipe flow DNB experiments by ANL

- Pressure: 138 bar

- Mass flux: $1650 \mathrm{~kg} / \mathrm{m}^{2} \mathrm{~s} \sim 2650 \mathrm{~kg} / \mathrm{m}^{2} \mathrm{~s}$

- Sub-cooled inlet temperature: $8.5 \mathrm{~K} \sim 96 \mathrm{~K}, 7.7 \mathrm{~mm}$ tube with $45 \mathrm{~cm}$ heated section Validation campaign 2: $5 \times 5$ fuel bundle DNB experiments by WEC

- Pressure: 70 160 bar

- Mass flux: $950 \mathrm{~kg} / \mathrm{m}^{2} \mathrm{~s} \sim 3622 \mathrm{~kg} / \mathrm{m}^{2} \mathrm{~s}$

- Sub-cooled inlet temperature: $4 \mathrm{~K} \sim 121 \mathrm{~K}$, spacers with mixing vane and no mixing vane

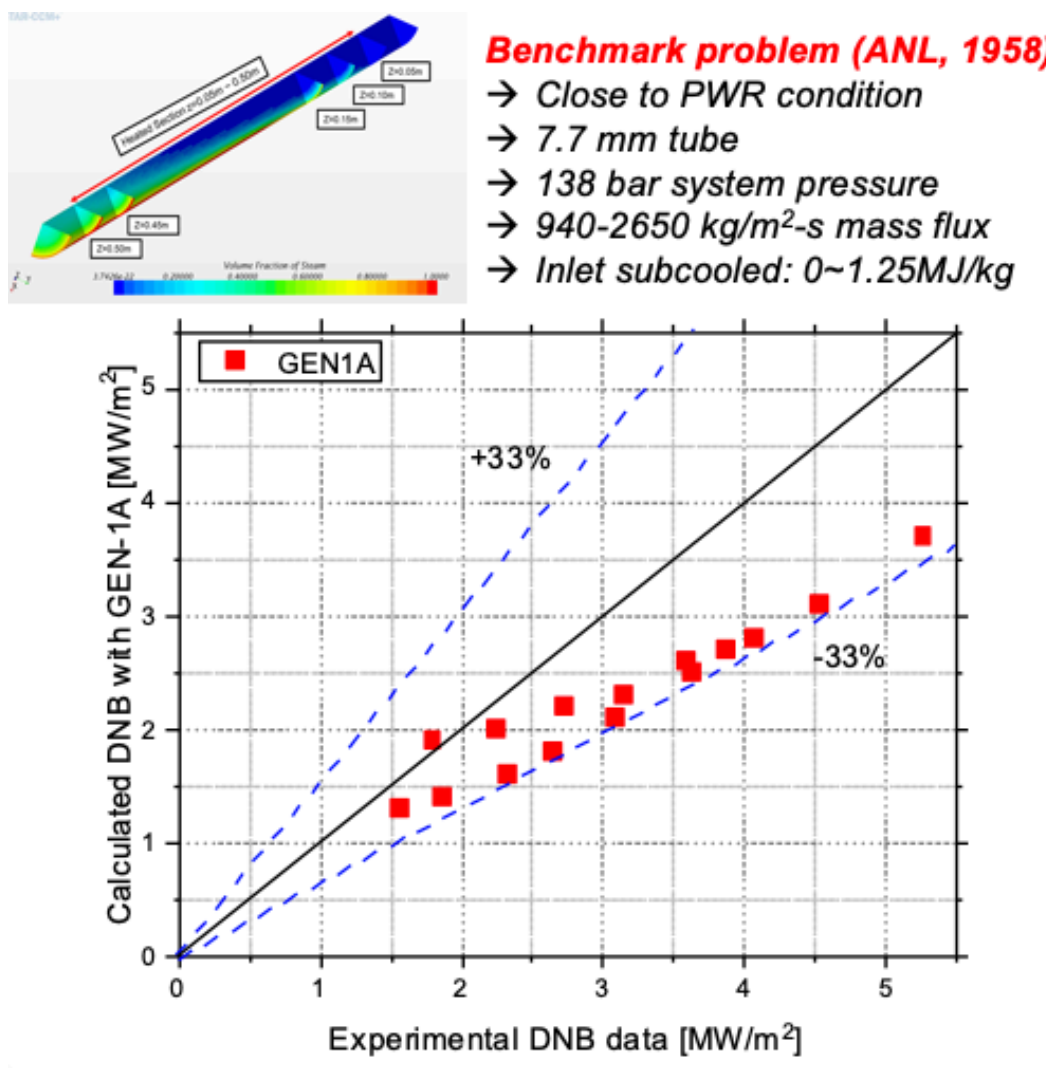

Figure 5 Results on DNB validation campaign 1 with original CASL model 
Both validation tests exhibit consistent trends of under-prediction of DNB in the simulation compared to the measurements. Overall deviations between measurement and calculation turn out to be around 33\% in the pipe flow test and 30 50\% underpredicted behavior in the $5 \times 5$ fuel bundle tests. Interestingly more notable under-predicted model behavior is observed with the mixing vane featured fuel bundle channel. It is believed that the turbulence mixing effect is more pronounced in the mixing vane flow channel and results in a larger deviation compared to the experiments. Those turbulence effects on the DNB are briefly investigated by applying various turbulence models for the MV-tests. Unfortunately, no clear correlation is observed in the current study, however, standard k-e turbulence turns out to be a most robust model for the DNB application in most of validation tests encompassing pipe flow to fuel bundle flow. Figure 5 shows an example of a comparison study for DNB model performance for the pipe flow application.

One of potential causes for under-prediction of DNB would be possible over-prediction of void creation at the heated wall due to inappropriate wall boiling closure, which might not be applicable for the high-pressure condition. As discussed in an earlier chapter, void creation in a subcooled boiling simulation is largely determined by an evaporation heat flux term on the wall and some extent of the lateral distribution term by interfacial momentum. Evaporation heat flux determines void mass flux at the heated wall as a void source term. Therefore, non-representative wall boiling closure for high pressure could lead to over-prediction of void creation, and the over-predicted void will trigger DNB detection at the low heat flux condition. Thus, under-predicted DNB values are readily obtained in most of the tests so far. Another issue would be incorrect void distribution due to inappropriate interfacial momentum transfer closure. Among many interfacial closures, lift and wall lubrication force would be the most relevant components that determine a lateral void fraction near the wall.

Those two components are heavily investigated in in the FY18 sensitivity study, and the CASL Gen1-FY19 model, introduced in the chapter 2, account for those modified closure terms. Void creation term by modified wall boiling closure and distribution term by new lateral interfacial momentum closures should particularly help improve the DNB performance compared to the previous model. The performance review between the original model and the modified FY19 model will be discussed in the section 3.4.

\subsection{Convergence check for the DNB tests}

From the experimental standpoint, transition of nucleation boiling to film boiling (i.e. DNB) is generally detected by monitoring wall temperature excursion. In the numerical DNB simulation, there is more than one way to detect the transition dynamic. In the current study, we utilized three monitoring variables to determine when the DNB is triggered in the course of incremental heat flux simulations: 1) max wall temperature monitoring, 2) wall dry-out factor (K-value), and 3) net energy transfer monitoring. To confidently quantify the DNB point in the simulation, checking all three monitoring points are recommended.

As described in Chapter 2, a transition from nucleate boiling mode to film boiling heat transfer model is solely determined by the wall dry-out factor, K-value (see equation 11). Figure 6 demonstrates when the K-value starts becoming a non-zero value as the heat flux is incrementally increased. At the same moment, the wall temperature is radically increasing as the heat transfer 
model is transitioning. Thirdly, net energy transfer is monitored to see if a numerical thermal equilibrium condition is achieved at each heat flux. Note that net energy transfer is being monitored by evaluating total energy transfer in the computational domain including liquid phase heat transfer, vapor phase heat transfer, and interfacial heat transfer. At the given heat flux condition, the energy balance should be zero once a thermo-equilibrium state is achieved in the simulation. It is noted that before DNB mode is triggered, the energy balance is always saturated to a zero value after sufficient iterations at the given heat flux. However, once the DNB mode is triggered, the energy balance at the heated wall becomes non-zero. This implies that the energy transfer at the wall is departing from the thermo-equilibrium condition when the DNB is triggered.
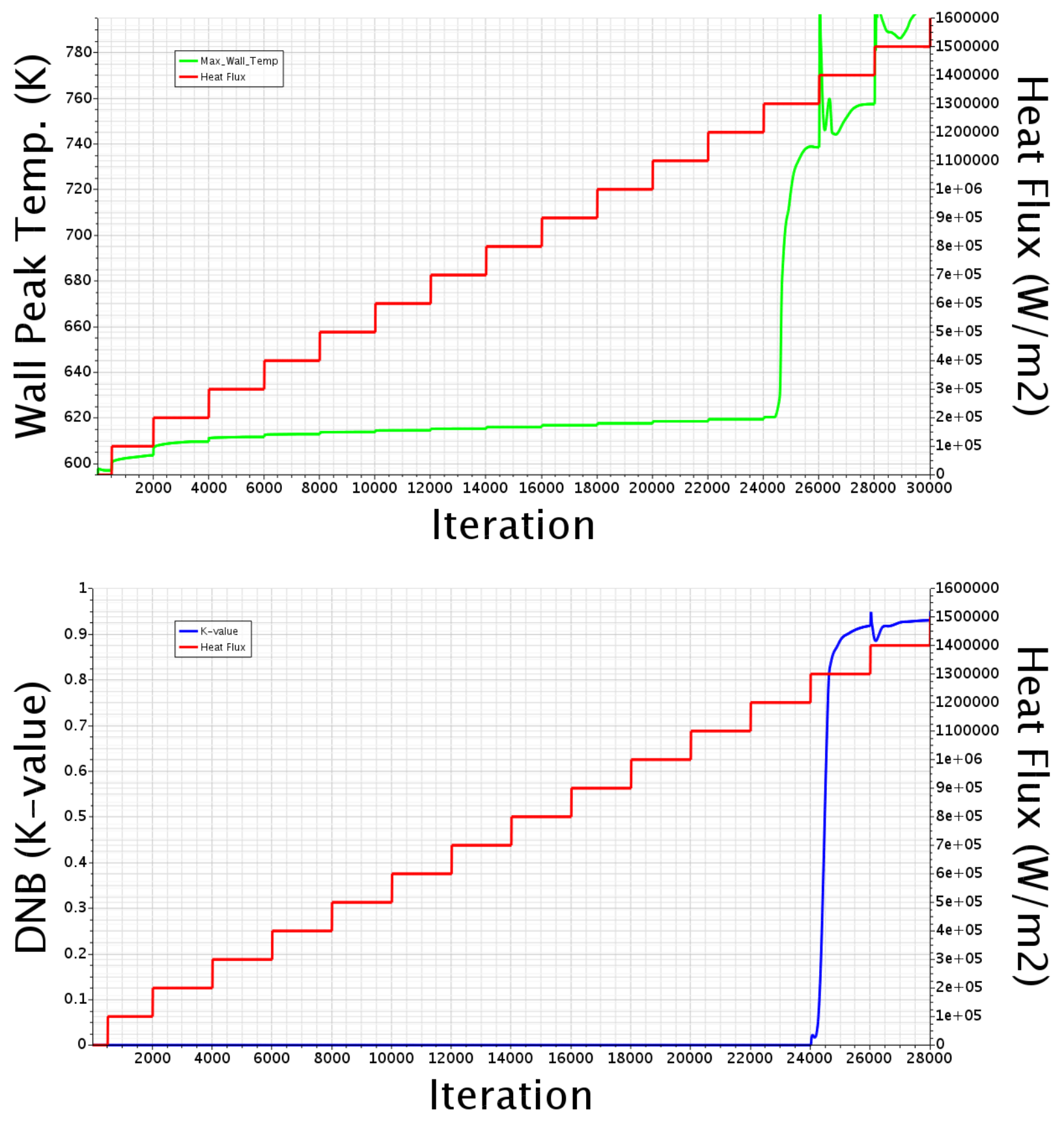


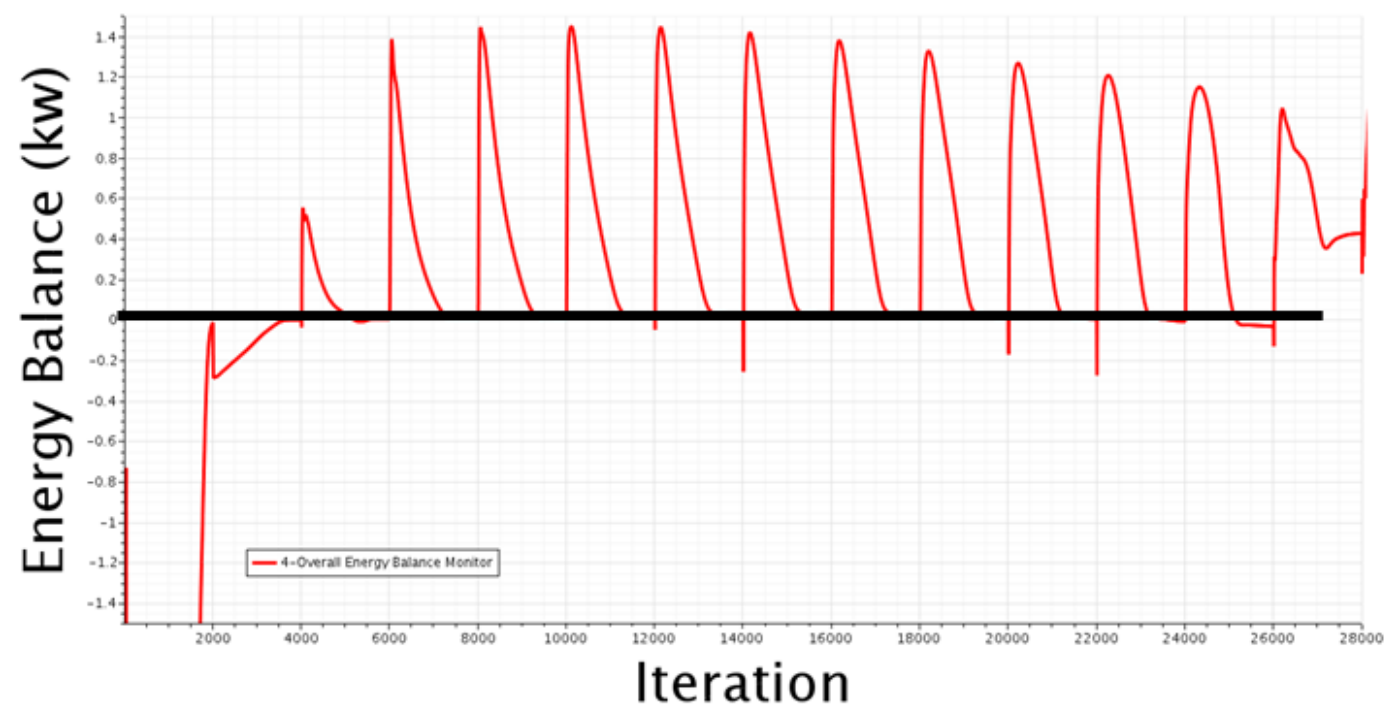

Figure 6 Wall temperature, K-value, Energy monitors with incremented heat flux up to DNB

Above Figures represent wall peak temperature, K-value, and net energy transfers monitoring value as the heat flux is increasing by $0.1 \mathrm{MW} / \mathrm{m} 2$ with 2000 iterations. Approximately when the heat flux is reaching to $1.4 \mathrm{MW} / \mathrm{m} 2$, all three monitoring points are indicating heat transfer model has changed and DNB has occurred.

\subsection{Axial and radial void characteristics with different heat flux conditions}

Here, we report temperature and corresponding density and void distribution calculated from the DNB simulation. At any given heat flux condition, the two-fluid approach will solve all of the fluid parameters in both phases as well as three-dimensional void distribution. Figure 7 graphically illustrates those calculated fluid parameters and potential DNB locations in the pile flow application.
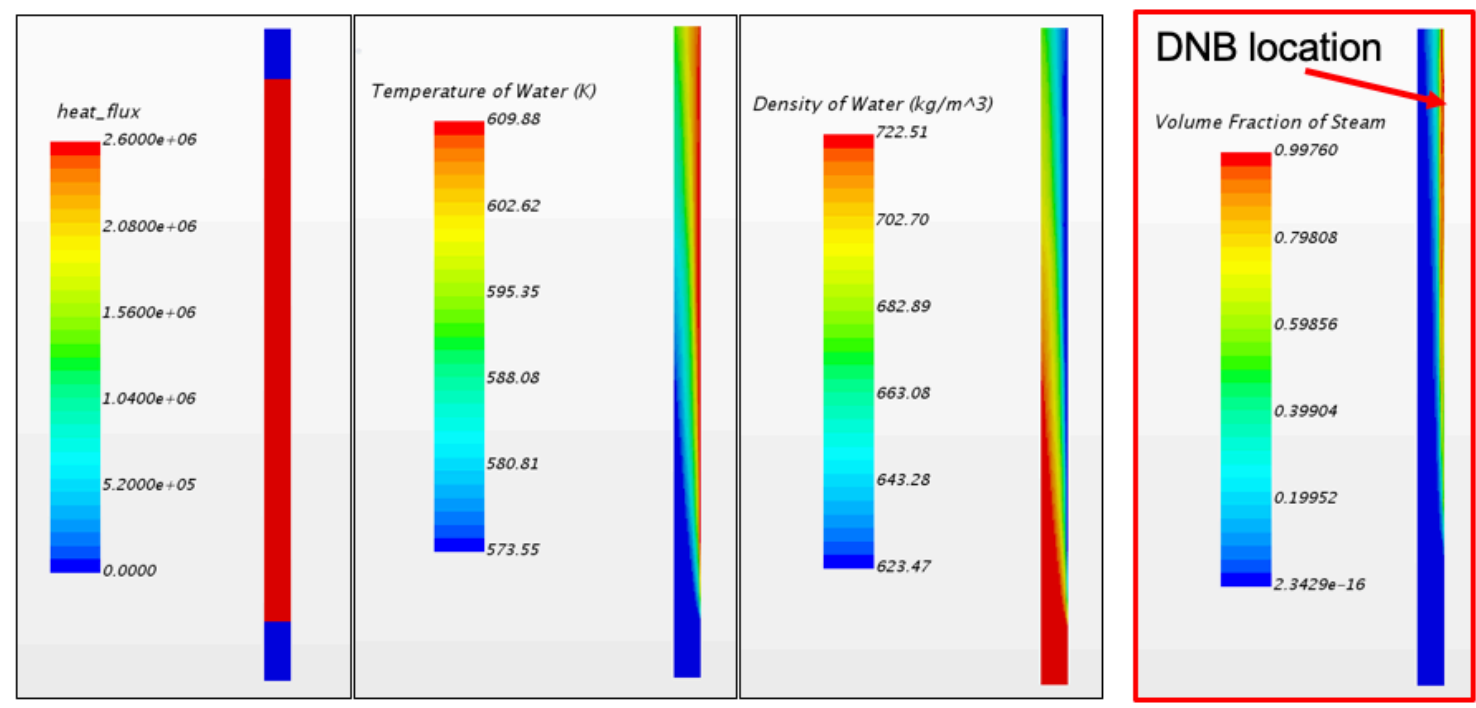

Figure 7 An example of temperature, density, and void profile calculation for the DNB test 


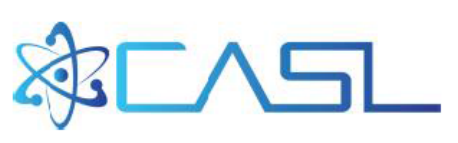

Generally, DNB occurs at the end of heated section when the heat flux is uniformly applied. So, a monitoring line probe is used to extract the radial void profile at the end of heated location, here $\mathrm{z}=500 \mathrm{~mm}$ from the inlet of pipe. A radial void distribution is reported along with four different heat flux conditions $(24 \%, 50 \%, 75 \%$, and $82.5 \%$ of CHF) as illustrated in Figure 8 . The horizontal axis is the radial position starting from the centerline of bulk flow region $(0.0 \mathrm{~mm})$ to the near wall region $(3.85 \mathrm{~mm})$. The vertical axis represents the corresponding void fraction. As heat flux increases, the wall boiling model kicks in and introduces wall boiling by producing bubbles from the wall. The void fraction near the wall is accumulated above 0.6 when the heat flux become $50 \%$ of CHF. Void profile observed in the current study indicates a wall-peak trend, which is observed in most subcooled flow boiling experiments with low void quality condition. Near wall voids tend beyond 0.9 when the heat flux gets close to $82.5 \%$ of critical heat flux. Without modifying the DNB triggering criterion (e.g. Y+ of 200 and local void of 0.9), under-predicted DNB in the current approach might be further improved by recalibrating the wall boiling closure for the high-pressure application as well as interfacial momentum transfer. Unfortunately, most of the DNB test does not record any of the wall boiling dynamics (bubble departure size, shape, nucleation size, departure frequency, and waiting time, etc.), but only focus on the DNB measurement. Thus, the lack of those bubble dynamic measurement or experimental boiling curve data significantly hinder the current DNB validation tests. In addition to the wall boiling validation, there must be huge room to improve the interfacial momentum closures (e.g. lift force, wall lubrication force, and mean bubble diameter) in the modeling if associated experimental data from either adiabatic two-phase test or boiling test at high pressure condition is available. This experimental research support should be more addressed in the future tasks of the CFD-based DNB simulation application.

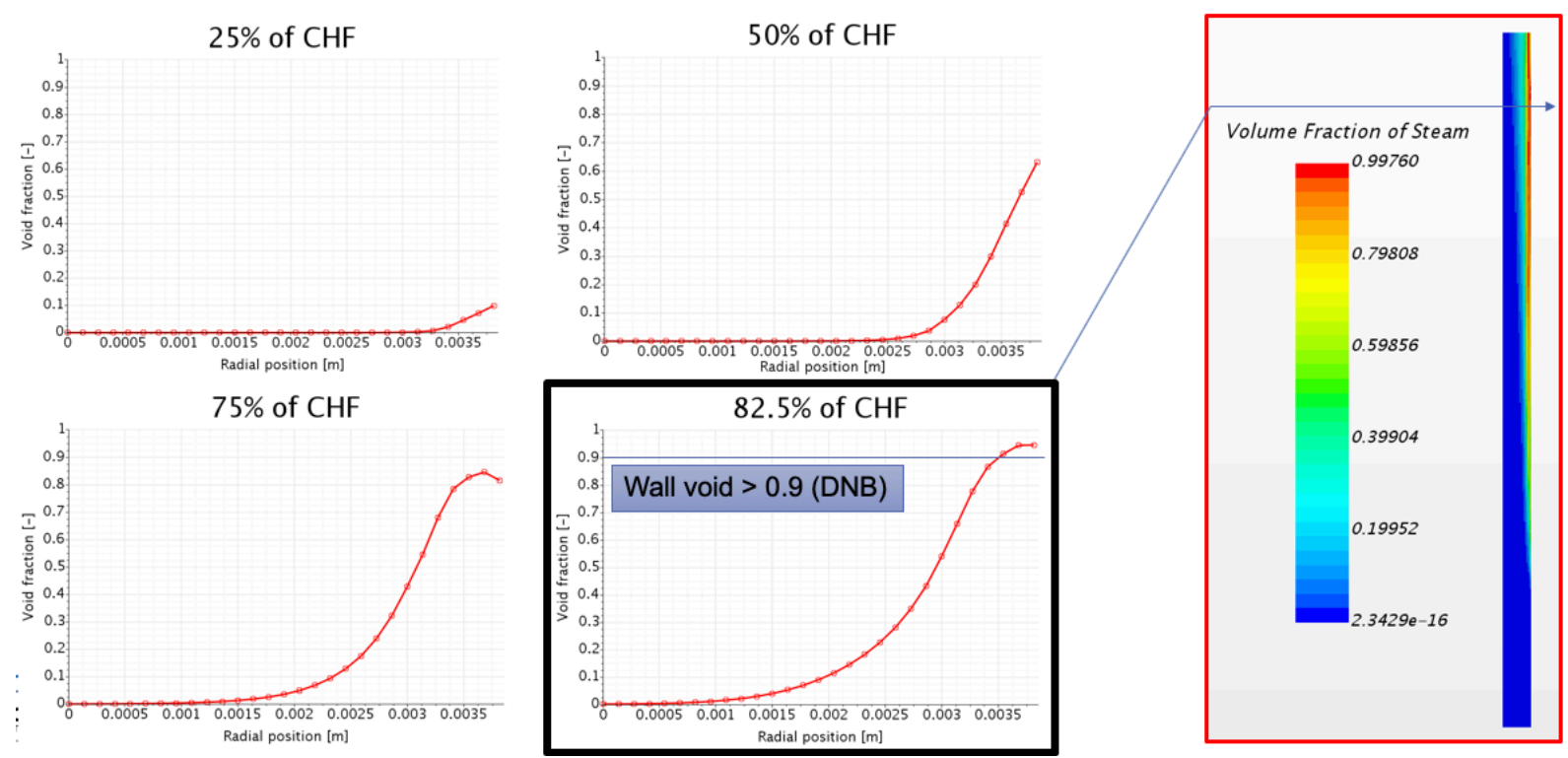

Figure 8 Radial void distribution along with increasing heat flux up to $82.5 \%$ of CHF

\subsection{DNB performance comparison between original model and modified model}

Here we report the comparative study of the DNB performance with modified Gen1-FY19 model against the original boiling model used in the previous campaign. While the Gen1-FY19 model is feasible to apply the complex flow channel like the $5 \times 5$ fuel bundle case, we largely focused on the 
pipe flow DNB validation in order to evaluate the sensitivity of the newly selected closure model for high pressure DNB applications. The virtual boiling test and DNB detection mechanism is identical to the method tested in the previous validation tests. For example, an operation test condition is selected from the DNB experimental report, a representative mesh is built up and a controlled heat flux profile (e.g. am incremental heat flux for the heated surface in the computational domain) is set for the virtual boiling test up to the DNB occurrence. The only change is a combination of selected closures in wall boiling and interfacial transfer terms. To clearly compare the difference in the selected closure setting, a comparison table is summarized in Table 3 below. The closures not mentioned below are set to be identical (see Table 2).

Table 3. Selected closure comparison between Gen1-FY17 and Gen1-FY19

\begin{tabular}{|c|c|c|}
\hline Selected closures & Gen1-FY17 (Original) & Gen1-FY19 (Modified) \\
\hline Lift force & No Lift & Sugrue lift \\
\hline Wall Lubrication force & No WL modeled & Lubchenko model \\
\hline Condensation model & Ran-Marshall & Kim-Park \\
\hline Interfacial Area Density & Spherical particle assumption & Symmetric assumption \\
\hline Interfacial length scale & Kurul-Podowski model & S-gamma model \\
\hline Bubble departure diameter & Tolubinski & Kocamustafaogullari \\
\hline Bubble departure frequency & Cole & Cole \\
\hline Nucleation site density & Lemmart-Chawla & Modified Li model \\
\hline
\end{tabular}



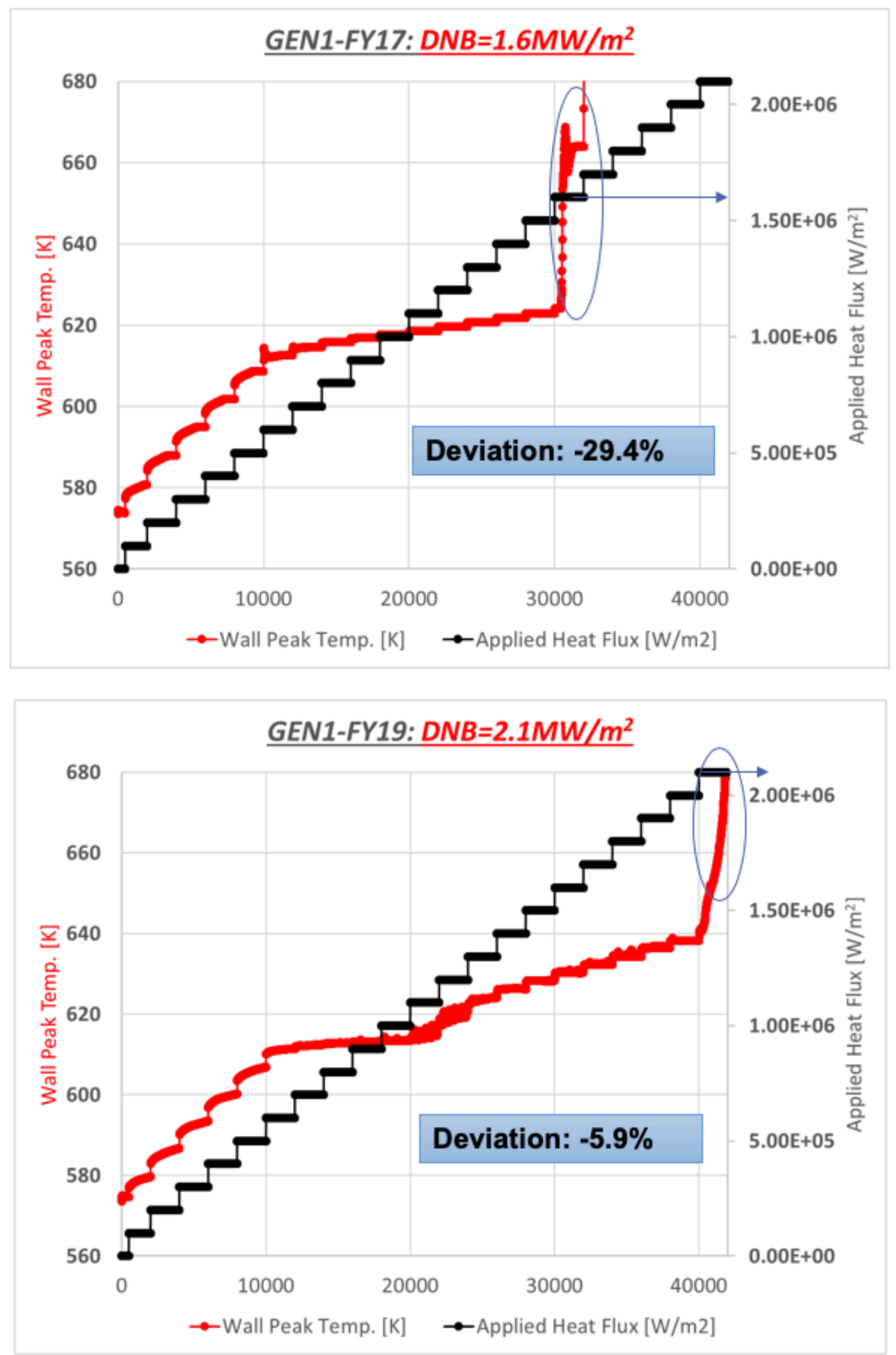

Figure 9 Wall peak temperature monitoring with incremental heat flux 
The results of the max. wall temperature along the incremental heat flux condition with two different boiling closure selections are illustrated in above. Note that an identical heat flux profile is applied in those two boiling tests for a direct comparison. The operating boiling test condition includes $\mathrm{P}=138$ bar, mass flux $=1653 \mathrm{~kg} / \mathrm{m}^{2}-\mathrm{s}$, and inlet subcooled temperature $=35 \mathrm{~K}$. the heat flux is incremented by $0.1 \mathrm{MW} / \mathrm{m} 2$ over 2000 iteration assuring thermal equilibrium condition is achieved in the numerical simulation. Figure 9 clearly exemplifies an improved DNB performance with a modified boiling model (i.e. Gen1-FY19) against the original model. The deviation between measurement and calculation is reduced to $-5.9 \%$ from $-29.4 \%$ for this specific test condition. This improvement is attributed to more realistic wall boiling closure selection for high pressure application as well as improved interfacial momentum closures which help avoiding over prediction of near wall void fraction at some extent. Further evaluation on improvement can be investigated with the help of experimental void profile measurement at the high-pressure boiling test as a future study. With this in mind, the validation with modified Gen1-FY19 model is extended over a wide range of test conditions, and the result of the DNB calculations are summarized below in Table 4.

Table 4. A direct comparison of DNB values between Gen1-FY17 and Gen1-FY19

\begin{tabular}{|c|c|c|}
\hline $\begin{array}{c}\text { ANL }(1963, \text { Weatherhead }) \\
\left(\mathrm{MW} / \mathrm{m}^{2}\right)\end{array}$ & $\begin{array}{c}\text { FY17 model } \\
\left(\mathrm{MW} / \mathrm{m}^{2}\right)\end{array}$ & $\begin{array}{c}\text { FY19 model } \\
\left(\mathrm{MW} / \mathrm{m}^{2}\right)\end{array}$ \\
\hline 4.069 & 2.8 & 3.0 \\
\hline 3.628 & 2.5 & 2.7 \\
\hline 3.091 & 2.1 & 2.3 \\
\hline 2.652 & 1.8 & 2.0 \\
\hline 2.234 & 1.6 & 2.1 \\
\hline 1.877 & 1.4 & 1.8 \\
\hline 1.571 & 1.3 & 1.5 \\
\hline 5.268 & 3.7 & 4.2 \\
\hline 4.543 & 3.1 & 3.5 \\
\hline 3.880 & 2.7 & 3.0 \\
\hline 3.596 & 2.6 & 2.8 \\
\hline 3.155 & 2.3 & 2.5 \\
\hline 2.729 & 2.1 & 2.2 \\
\hline 2.256 & 2.0 & 2.1 \\
\hline 1.798 & 1.9 & 1.8 \\
\hline & & \\
\hline
\end{tabular}

The overall predictive performance of the DNB simulation is improved with a modified boiling model as summarized in the Figure 10. Those improvement on DNB performance should be further investigated in term of robustness and applicability in the various flow channel design such as fuel bundle configuration with and without mixing vane spacers. From the numerical robustness standpoint, most tests in the current study (e.g. pipe flow configuration) demonstrate a viable numerical robustness and stability up to the DNB point. However, it is worth noting that some of the high subcooled test conditions still exhibit some numerical instability when the heat flux is close to the DNB point. This numerical instability issue should be further investigated in both closure sensitivity level tests and DNB tests in a complex flow channel test. In parallel to the current study, WEC is testing same boiling model (i.e. Gen1-FY19) with $5 \times 5$ fuel bundle configuration to 


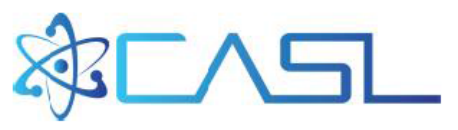

evaluate how much improvement can be gained with the Gen1-FY19 model. The associated results on $5 \times 5$ fuel bundle test can be reference to Brewster's work [10].

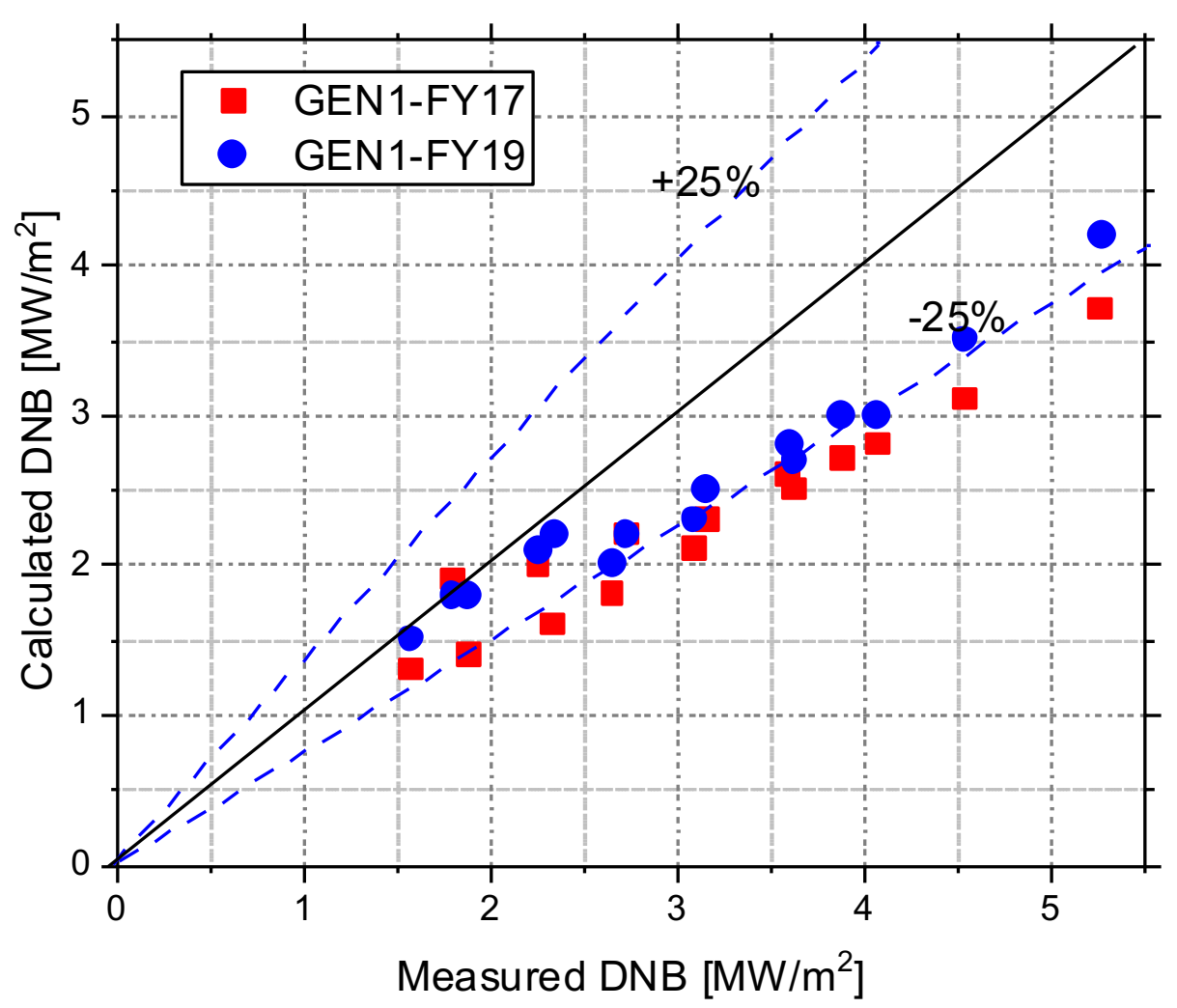

Figure 10 Prediction performance evaluation by comparing measurements vs calculations

Among the current test results, the DNB performance is reviewed along with different subcooled temperatures. 5 test cases with different subcooled conditions are carefully selected while all other operating conditions are kept identical. The subcooled temperature varies from $12 \mathrm{~K}$ to $60 \mathrm{~K}$, two different subcooled groups are divided: one with low subcooled condition (less than $35 \mathrm{~K}$ subcooled from the saturation temperature), and the other group with high subcooled condition (more than $40 \mathrm{~K}$ subcooled inlet temperature). Interestingly the low subcooled group shows notably good predictive capabilities (exhibiting less than $7 \%$ deviation from the measurements) while the high subcooled group makes relatively larger deviation compared to the low subcooled group.

This observation indicates that the modified boiling model is well calibrated to the low subcooled flow boiling application and quenching closure needs to be further investigated for the high subcooled flow boiling application. It is believed that bubble influence area coefficient and bubble growth waiting time in equation (13) should be re-adjusted for high subcooled flow boiling application at high pressure conditions. Those kinds of closure adjustment require appropriate experimental measurements from high resolution flow visualization technique. However, from this subcooled level effect on the DNB via grouping study illustrated in the Figure 11, the current DNB 


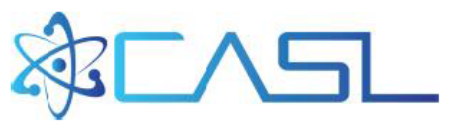

model (i.e. Gen1-FY19 closure set) is sufficiently applicable for CFD-based DNB test at PWR-like operation conditions (high pressure and low subcooled flow condition) with reasonable predictive capability.

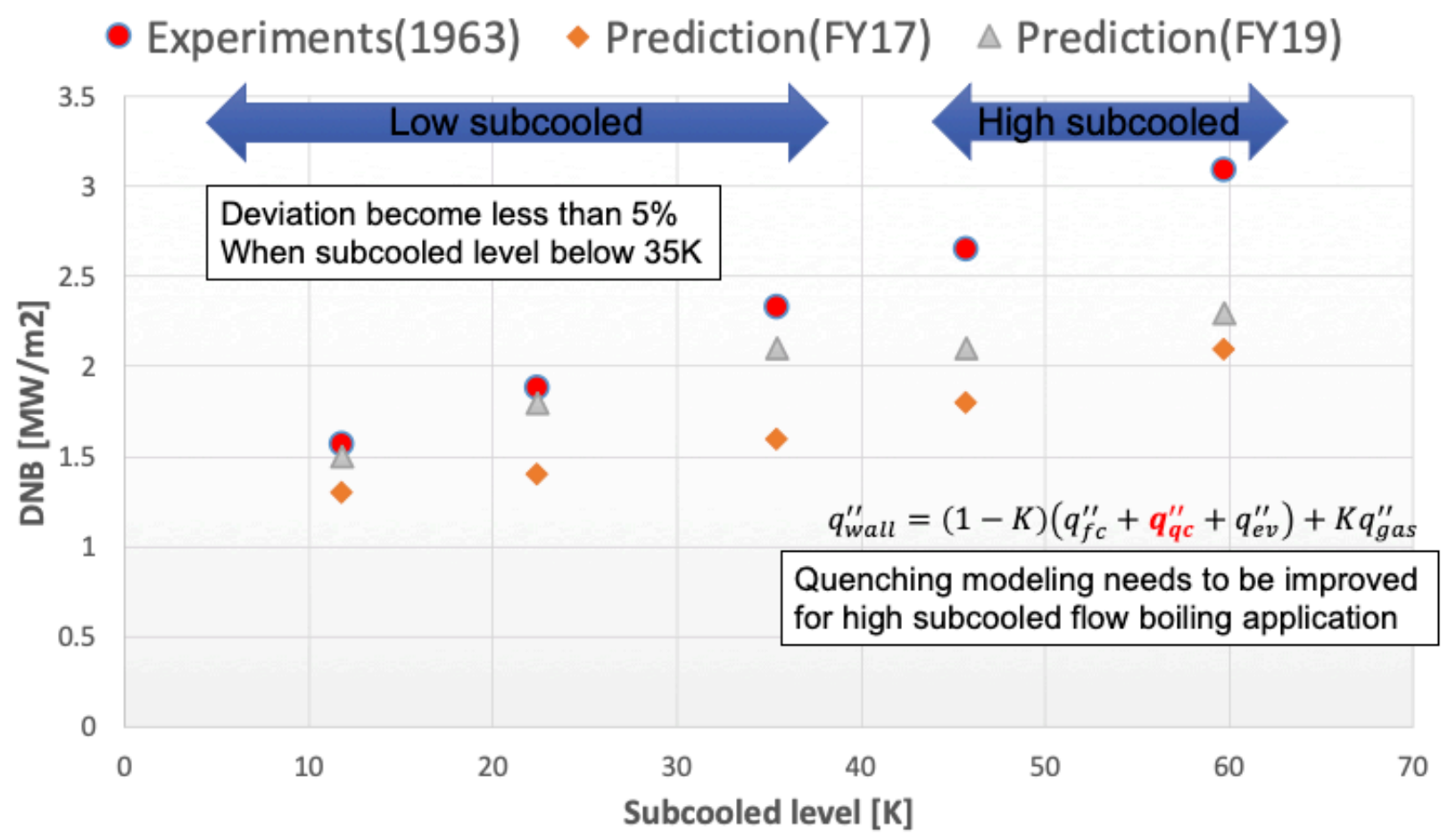

Figure 11 DNB performance with different subcooled inlet temperature levels 


\section{L3.THM.DNB.P19.03}

\section{Conclusions and suggested future works}

Over the past four years, CASL THM have extensively investigated a state of art M-CFD approach to provide a high-fidelity DNB simulation capability based on two-fluid Eulerian framework in conjunction with a wall heat flux partitioning model. The overarching goal in this task is to develop and demonstrate a robust M-CFD model capable of predicting an entire boiling history up to the DNB condition in which the wall boiling mode is transitioning from the nucleate boiling mode to the film boiling mode. Three different flow channel configurations were studied and a thorough closure sensitivity study were performed to evaluate the wall boiling and momentum closure effect on the DNB performance. A robust and physically well representing boiling closure model is proposed based on a series of previous studies. The Gen-1-FY19 DNB model is evaluated with reference to experimental measurement resulting in an improved predictive trend compared to the original model. Below are a high-level summary of the current study and some suggested future works as follows

- The CASL baseline model was developed and tested for pipe flow DNB test in FY16. DNB prediction methodology using M-CFD approach was proposed to evaluate the predictive performance. Predicated DNB was compared to the measurement in high pressure pipe flow DNB test showing under-predictive behavior up to $33 \%$ deviation.

- In FY17, we tested 5x5 fuel bundle flow configuration DNB test with and without mixing vane spacer grids. The same model was tested in a more realistic PWR-like flow channel. Under-predictive behaviors were still shown in these tests. The deviations from the measurements are varied from $-25 \sim-50 \%$. Note that the mixing vane test case exhibit relatively larger deviation compared to the non-mixing vane test.

- In FY18, we scrutinized the baseline boiling model and identified what would be the potential cause of under-prediction. Based on closure sensitivity study, a modified boiling closure model (i.e. Gen1-FY19) is introduced for further validations

- Gen1-FY19 model includes following changes: 1) improved wall boiling closure for high pressure subcooled boiling applications. Newly calibrated bubble departure diameter and nucleating site density are implemented, 2) realistic interfacial momentum transfer closures (a bubble shape considered lift and wall lubrication forces, and advanced bubble size distribution with the S-gamma model) are applied, and 3) bulk region condensation model is modified.

- The modified boiling model exhibits an improved DNB predictive behavior against the original model while maintaining a viable robustness in the virtual boiling test.

- If experimental measurements for high pressure subcooled boiling are available, the modified boiling model should be further validated with more than just DNB values such as axial and radial void profile in the flow channel, wall superheated condition, and wall boiling characteristics.

- Nonetheless, the Gen1-FY19 model is still a feasible option for high pressure DNB application with reasonable accuracy (less than $24 \%$ deviation from the measurements) while viable robustness is achieved in most of tests. In addition, at a PWR like subcooled condition (subcooling level below than $40 \mathrm{~K}$, and high pressure), the current model demonstrates even improved predictive trend (the deviation falls below $10 \%$ ). 


\section{References}

1. Seung Jun Kim, Emilio Baglietto, Etienne Demarly, LA-UR-16-28815, "Evaluation of DNB predictive capability in multiphase boiling model of STAR-CCM+", L3.THM.CFD.P13.04

2. Seung Jun Kim, LA-UR-17-21026, "Evaluation of CASL boiling model for DNB performance in full scale $5 \times 5$ fuel bundle with spacer grids", L3.THM.CLS.P15.02

3. Seung Jun Kim, LA-UR-18-28198, "A status review on DNB prediction using CASL baseline boiling model and possible suggestions regarding wall boiling closures", L3.THM.DNB.P17.02

4. J. Weisman and B. S. Pei, Prediction of critical heat flux in flow boiling at low qualities, Int. J. Heat Mas Transfer 26, 1463-1477 (1983).

5. Be Magolan, Emilio Baglietto, "Assembling a Bubble-Induced Turbulence Model Incorporating Physical Understanding from DNB", International Journal of Multiphase Flow 116, 185-202 (2019).

6. Tomiyama, A., Kataoka, I., Zun, L., Sakguchi, T., 1998. Drag coefficients of single bubbles under normal and micro gravity conditions. JSME Int. J., Ser. B 41, 472-479

7. Sugrue, R.M., "A robust momentum closure approach for multiphase computational fluid dynamics applications”, Doctoral Dissertation, MIT, 2017

8. Lubchenko, N., Magolan, B., Sugrue, R. and Baglietto, E., "A more fundamental wall lubrication force from turbulent dispersion regularization for multiphase CFD applications", Int. J. Multiphase Flow, Vol. 98, pp. 36-44, 2018.

9. Lo, S., Rao, P., 2007. Modeling of droplet breakup and coalescence in an oil-water pipeline. In: $6^{\text {th }}$ international conference on Multiphase Flow, ICMF 2007, PP. 9-13

10. Robert A. Brewster, Jinyong Feng, Emilio Baglietto "Industry Application of CASL DNB Methods", L2.THM.DNB.P19.01 